\title{
Indicadores de desempenho para fretes rodoviários: estudo de caso aplicado à empresa do segmento de confecções
}

\author{
Performance indicators for road freight: \\ a case study applied to a company of the garment industry
}

Letícia Sandrin Graduação em Administração de Empresas. Universidade Federal da Fronteira Sul (UFFS) - Brasil. leticia_sandrin@hotmail.com.br

Moacir Francisco Deimling Doutor em Engenharia da Produção. Universidade Federal da Fronteira Sul (UFFS), - Brasil. moacir.deimling@uffs.edu.br

\section{RESUMO}

Com a competitividade do mercado é comum que as empresas busquem alternativas para promover a sustentabilidade empresarial, otimizando assim os resultados. Considerando os custos, é importante controlálos de forma que se tenha gestão para aqueles valores de maior proporção. Ao identificar que os custos com logística representam de $4 \%$ a $30 \%$ das vendas, e fretes com distribuição física oscilam de $7 \%$ a $9 \%$, identificase relevância na execução desse controle. A presente pesquisa possui o objetivo de analisar indicadores para ponderar serviços terceirizados de fretes pagos, em uma indústria do ramo de confecções. A metodologia empregada é caracterizada quanto aos fins de abordagem mista com predominância quantitativa e uma pesquisa aplicada. Quanto aos meios é considerada de campo e estudo de caso. $O$ estudo possibilitou levantar indicadores de desempenho de fretes e projetá-los na contratação do serviço. A inferência permitiu construir indicadores que possibilitam realizar apreciações tanto qualitativas do frete terceirizado, quanto quantitativas.

Palavras-chave: Logística. Frete. Indicadores. Desempenho.

\begin{abstract}
Due to the existing market competitiveness, it is common that the companies seek alternatives to promote business sustainability, thus optimizing the results. Considering costs, it is important to control them so there is management for those values with larger proportion. By identifying that costs with logistics represent from $4 \%$ to $30 \%$ of the sales and freight with physical distribution oscillate from $7 \%$ to $9 \%$, such control becomes relevant. The research has the objective of analyzing indicators to consider outsourced freight services paid in a garment industry. Concerning purposes, the methodology applied was of a mixed approach with quantitative predominance and an applied research. Regarding means, it is a field research and a case study. The study enabled to present some performance indicators for freight and project them in the hiring of the services. The inference made it possible to build indicators that allow for assessments both qualitative and quantitative of the outsourced freight.
\end{abstract}

Keywords: Logistics. Freight. Performance. Indicators.

Recebido em 08/01/2019. Aprovado em 26/04/2019. Avaliado pelo sistema double blind peer review. Publicado conforme normas da ABNT. http://dx.doi.org/10.22279/navus.2019.v9n4.p125-138.896 


\section{INTRODUÇÃO}

Frente à alta competitividade e a busca constante por redução de custos empresariais, é relevante que as empresas identifiquem modelos de gestão sustentáveis. Considerando que esta atitude repercute diretamente nos resultados organizacionais e desempenho. Quando a empresa depende de terceiros para realizar serviços como o transporte e frete rodoviário, é relevante monitorar a atividade por meio de controles dos valores realizados, onde possivelmente se identificam perdas e gastos em pontos críticos.

De acordo uma pesquisa realizada pela Fundação Dom Cabral (2017), as empresas que realizam transporte de mercadorias em longas distâncias acabam por terceirizar o frete e os operadores logísticos, porque ao terceirizar a empresa transforma o custo fixo em variável.

Ballou (2006) aponta que os custos com logística abrangem $4 \%$ a $30 \%$ das vendas, sendo que fretes com distribuição física oscilam de 7\% a 9\% sobre vendas. Mesmo com percentual isolado, é relevante avaliálo pois pode ser o maior encarecedor dos custos substanciais do produto. Para Ballou (2006), o valor pode perder apenas para o Custo do Produto Vendido (CPV), que constitui de $50 \%$ até $60 \%$ do produto.

A Confederação Nacional do Transporte (CNT, 2014) ressalta que em 2014 os custos relativos ao modal rodoviário juntamente com a defasagem dos preços, provocaram elevação de $14 \%$ no valor do preço do frete para as cargas fracionadas, quando comparado ao ano anterior. $\mathrm{O}$ crescimento pode ser justificado pela elevação de $17,2 \%$ do diesel, $10 \%$ sobre a folha de pagamento e $12,7 \%$ sobre o preço dos pneus. Também pelos gargalos presentes na infraestrutura como: restrições à circulação em algumas regiões, escassez da mão de obra qualificada e rodovias.

Em uma pesquisa realizada pela Fundação Dom Cabral (2017), com cerca de 142 empresas brasileiras de 22 segmentos industriais diferentes se constatou que em média $11,73 \%$ da receita das empresas brasileiras é consumida pelo custo logístico, isso representa um aumento de 1,8\% do percentual quando comparado ao ano de 2014. A chamada inflação logística é mais representativa nas empresas que trabalham com distâncias maiores acarretando assim em um problema econômico e social, porque geralmente as classes mais baixas sentem o impacto primeiro.

Por meio de uma avaliação constante do montante utilizado com logística, tem-se o conhecimento de como se comporta o valor e das alternativas mais amenas para realizar investimento. Tal situação pode ser obtida por meio da elaboração e fixação de indicadores de desempenho, que ocasiona controle e permite analisar o comportamento do serviço sobre os mais variados aspectos (FISCHMANN; ZILBER, 1999).

Ao avaliar o contexto de forma qualitativa, objetiva-se identificar se o transportador atende demandas referente à qualidade. Quantitativamente, identifica-se questões referentes ao transporte e caso supre as expectativas do contratante, no que tange ao preço (MARTINS; LOBO; ARAÚJO, 2005).

Os indicadores de desempenho surgiram com objetivo de sistematizar, acompanhar e implementar diretrizes a fim de garantir satisfação dos stakeholders (MARTINS; COSTA NETO, 1998). Ou seja, com as análises mediante a aplicação de indicadores, é possível avaliar a situação passada e atual que possibilita julgar os fatos para tomar uma decisão assertiva (PERREIRA, 2001).

Para que isto ocorra é importante organizar os dados visando aplicar os indicadores de desempenho e após, estruturar os processos de avaliação. Esse alinhamento permite avaliar os serviços logísticos, com objeto de permitir possíveis direcionamentos estratégicos no mercado.

Diante deste aspecto, a pesquisa possui como problemática: Quais são os indicadores que podem ser utilizados para avaliar os processos referentes aos fretes rodoviários pagos, em uma indústria do ramo de confecções? Tem como objetivo geral: Analisar indicadores para ponderar serviços terceirizados de fretes pagos, em uma indústria do ramo de confecções.

Na seção introdução, apresentou-se o assunto, problema e objetivo de estudo, juntamente com a contextualização. Após, será apresentado um resgate teórico, que trata dos indicadores de desempenho. Em seguida, apresentar a metodologia que dita os procedimentos metodológicos, que serão à base da análise e apresentação dos dados. No item estudo de caso, será detalhado o trabalho realizado junto à empresa Gama. Por fim, serão apreciadas as considerações finais. 


\section{REFERENCIAL TEÓRICO}

Diante da intensa competitividade existente no ambiente externo, as empresas sobrevivem sob um contexto cada vez mais complexo e dinâmico. O comportamento das organizações, diante dessa realidade, também pode impactar nos resultados e desempenho.

Taboada (2009) estuda o comportamento das empresas frente a um ambiente de alta competitividade. Uma empresa com comportamento reativo pode passar por grandes riscos, enquanto que aquela empresa com comportamento ativo torna-se dinâmica às ações no mercado.

É importante que a empresa identifique os pontos a serem melhorados e qual a proporcionalidade diante dos demais, para então aperfeiçoar-se. Uma alternativa de melhoria pode ser através do conhecimento dos seus custos, gastos e investimentos.

Ao considerar a realidade organizacional mediante a utilização de fretes, compreende-se como um ponto determinante a análise de qual modal utilizar no transporte. Para Dias (2012), é possível utilizar diversos modais, todavia, deve ocorrer uma seleção coesa, para isto é importante analisar primeiramente a viabilidade de cada um.

Das modalidades de transporte existentes, Castiglioni e Nascimento (2014) dividem o transporte terrestre, que pode ser: rodoviária, ferroviária e dutoviária. A modalidade aquaviária consiste nas opções: marítima, hidroviária (fluvial) e lacustre/cabotagem (costa marítima), ainda há a modalidade aérea, que é o transporte aeroviário.

Existem distinções entre transporte modal e intermodal. Sendo que o primeiro envolve o descolamento da carga através de apenas um meio de transporte, já o segundo, consiste na utilização de vários meios de transportes. No caso do intermodal, "um único transportador organiza todo o transporte, desde o ponto de origem, via um ou mais pontos de interligação, até o ponto ou porto final" (CASTIGLIONI; NASCIMENTO, 2014, p. 57).

No estudo realizado por Bowersox et al. (2014), são classificadas as características operacionais dos modais em relação à velocidade, à disponibilidade, à confiabilidade, à capacidade e à frequência. A Tabela 1 mostra o total destas características, sendo que as colunas com menor ponderação são as mais vantajosas.

Tabela 1 - Classificação das características operacionais dos modais de transporte

\begin{tabular}{c|c|c|c|c|c}
\hline $\begin{array}{c}\text { Características } \\
\text { operacionais }\end{array}$ & Ferroviário & Rodoviário & Hidroviário & Dutoviário & Aéreo \\
Velocidade & 3 & 2 & 4 & 5 & 1 \\
Disponibilidade & 2 & 1 & 4 & 5 & 3 \\
Confiabilidade & 3 & 2 & 4 & 1 & 5 \\
Capacidade & 2 & 3 & 1 & 1 & 4 \\
Frequência & 4 & 2 & 5 & $\mathbf{1 7}$ & 3 \\
Total & $\mathbf{1 4}$ & $\mathbf{1 0}$ & $\mathbf{1 8}$ & $\mathbf{1 6}$ \\
\hline
\end{tabular}

Fonte: Adaptado de Bowersox et al. (2014, p. 211).

Percebe-se que o modal rodoviário além de ser o mais acessado em território nacional, é o que possui a melhor classificação total. Castiglioni e Nascimento (2014) apontam vantagens deste modal, como: simplicidade no atendimento de demandas em pequenas e médias distâncias, agilidade no acesso e menor manuseio da carga, menor exigência de embalagens, possibilita um atendimento de porta a porta com apenas uma operação de carga (origem) e descarga (destino). Também permite maior frequência e alternativas de acesso, flexibilidade na manipulação de cargas e facilidade na substituição de veículos.

Como desvantagens os autores apontam o custo do frete elevado em alguns casos, menor capacidade de carga quando comparado aos demais modais e pouco competitivo para longa distância. É possível apontar que este modal é sensível em relação ao aumento dos preços com combustíveis, e, como se cogita a possibilidade de haver privatização das rodovias, isto pode gerar um aumento relativo nos valores com pedágios e seguros com roubo de cargas (CASTIGLIONI; NASCIMENTO, 2014; VIEIRA, 2003). Por isso, 
empresas que possuem o transporte de mercadorias como uma atividade imprescindível, precisam pesquisar opções para realizar a gestão dos fretes.

Existem muitos métodos de análises com indicadores considerados eficazes para uma empresa obter vantagem, mediante a alta competitividade empresarial, é possível citar a organização e a estruturação de informações, que podem ser analisadas mediante indicadores de desempenho.

Perreira (2001) aponta que para uma empresa obter vantagem perante seus competidores, é importante ter informações estruturadas e esquematizadas. Sendo possível utilizar indicadores e ferramentas em prol de atuar estrategicamente com vistas no longo prazo.

O autor ainda argumenta que indicadores de desempenho são métodos utilizados para avaliar uma determinada situação, sejam fatos, ideias e objetivos presentes em um determinado contexto (PERREIRA, 2001). Através dessa avaliação é possível nortear-se racionalmente para que a tomada de decisão seja assertiva. Ao considerar competitividade como um fator crescente, é importante que a empresa use ferramentas que possibilitem obter diferenciação, a seção seguinte explica os indicadores que podem ser utilizados na análise do frete.

\subsection{Indicadores de desempenho na gestão do frete rodoviário}

A aplicação dos indicadores de desempenho nos conhecimentos de frete se dá, na visão de Perreira (2001), para auxiliar na análise de desempenho diante de uma determinada atividade e isto, proporciona a gestão eficaz. A partir de então, apresenta-se um conjunto de indicadores de desempenho que norteiam a empresa em relação ao gerenciamento dos fretes.

Ângelo (2005) comenta em seu estudo a importância do indicador que realiza a relação entre o frete e vendas, ou também, Freight Costs as \% of Sales (Frete R\$ /Nendas R\$). Este indicador demonstra qual a participação do valor gasto com transportes sobre o total das vendas, ainda o autor comenta que a proporção é variável de negócio para negócio, por isto é importante estabelecer um padrão e buscar analisá-lo periodicamente.

Outro indicador proposto por Ângelo (2005) é a relação valor do frete e unidade expedida (Frete (R\$) / unidades expedidas). Este parâmetro objetiva compreender o valor de transporte que cada unidade possui, com isto é possível analisar a viabilidade de outros modais de transportes.

Propõem-se ainda, o indicador que examina as coletas realizadas no prazo acordado, ou On Time Pickups (Coletas no prazo/Total de coletas), nacionalmente este indicador possui um padrão, que pode variar de $95 \%$ a $98 \%$ (ÂNGELO, 2005).

Ângelo (2005) cita o indicador para erros de cobrança dos conhecimentos de transporte, ou Freight Bill Accuracy, com intuito de mensurar a proporção dos erros dos conhecimentos em relação aos valores totais de transportes. O cálculo é realizado por meio da divisão do erro de cobrança (R\$) pelo valor de transporte $(\mathrm{R} \$)$, nacionalmente esta média é de $98,5 \%$.

Ballou (2006) corrobora com os indicadores teorizados por Ângelo, quando comenta que o processo logístico é sensível a algumas características do produto, como: peso, volume, cubagem, valor da mercadoria e risco de transporte. Para Ballou (2006) todos esses coeficientes devem ser avaliados constantemente, por meio de indicadores e padrões próprios.

Conforme a precificação do frete, a transportadora pode obter maiores lucros ou resultar prejuízo. De acordo com Fleury, Avila e Wanke (1997) existem formas usuais para precificar o serviço. Pode ser conforme a característica da carga, ou seja, de acordo com peso da mercadoria, unidades, cubagem, valor da Nota Fiscal ou outras generalidades. Ou então pode abranger a contratação exclusiva que ocorre tradicionalmente mediante o custeio por quilometro rodado (FLEURY; AVILA; WANKE, 1997).

O método escolhido pode impactar no preço do frete, ao considerar que a empresa em estudo utiliza o primeiro método, que é através da característica da carga em que geralmente se utiliza o peso e a cubagem. Cabe então centrar-se nesse método para análise do estudo em questão (FLEURY; AVILA; WANKE, 1997).

Rita (2016) aponta que é importante realizar análises referentes ao perfil dos transportadores, seus concorrentes e o modo como o frete é contratado. A autora faz uma análise em seu estudo referente a 
contratação de autônomos versus transportadoras, no que tange a realização dos serviços de fretes. Também, aprecia o frete por distância, a fim de identificar qual é a predominância e quais padrões seguem diante dos respectivos volumes movimentados.

A partir dos indicadores e métodos de análise citados, é possível construir medidas avaliativas para a realização da negociação com transportadoras. A seção seguinte apresenta a metodologia de estudo aplicada.

\section{METODOLOGIA DA PESQUISA}

Para Vergara (2013) a caracterização pode se dar quanto aos fins e quanto aos meios. Quanto aos fins, essa pesquisa pode ser de abordagem mista, com predominância quantitativa e aplicada. E quanto aos meios, pode ser de campo e estudo de caso.

Para Creswell (2010) é possível haver a união de dados quantitativos e qualitativos em um estudo, podendo ser classificada como de abordagem mista. Para Appolinário (2012, p. 60), "as pesquisas se encontrarão em algum ponto contínuo, tendendo mais para um lado ou para outro", portanto, a presente pesquisa possui abordagem com predominância quantitativa, dado momento que aplica grandezas ou quantidade do fator presente, como proporções e usos de indicadores para determinação dos resultados (LAKATOS; MARCONI, 2011). Neste caso, foram representados tabelas e gráficos.

É uma pesquisa aplicada porque pretende resolver problemas reais, sejam eles, imediatos ou não. Embasa-se na teoria para interpretar, levantar dados, fundamentá-los e propor soluções específicas a partir de uma aplicação prática (VERGARA, 2013). Por isto que o presente estudo pretende identificar o problema exposto que compreende na gestão dos fretes e a partir disto, com uma metodologia adaptada à realidade organizacional propor soluções aos problemas específicos.

Quanto aos meios, é possível apontar que é uma pesquisa de campo, porque, tem como objetivo conseguir informações e conhecimentos acerca de um problema, em que se busca uma resposta ou hipótese com finalidade de descobrir fenômenos e relações entre variáveis (LAKATOS; MARCONI, 2011; VERGARA, 2013). Também se pode considerar que é de campo porque realizou-se no local do fenômeno a ser estudado, neste caso os setores envolvidos com o problema do Grupo Gama (VERGARA, 2013).

É um estudo de caso porque a presente pesquisa analisa a perspectiva da organização acerca da gestão dos fretes. $O$ estudo de caso é um método de ascender uma possível decisão, ou um conjunto de decisões que são tomadas com finalidade de implementar um resultado (YIN, 2010).

No que tange a coleta e análise dos dados, por se tratar de uma pesquisa mista a coleta de dados ocorre concomitantemente. Ao mesmo passo que se coletavam dados quantitativos referentes aos Conhecimentos de Fretes, buscavam-se realizar inferências qualitativas.

Isto ocorre devido a possibilidade de obter insights através da combinação das pesquisas qualitativas e quantitativas ao contrário de quando tratadas de formas isoladas, uma vez que o uso combinado deste estudo possibilita melhor compreensão dos problemas da pesquisa (CRESWELL, 2010).

Os sujeitos da pesquisa foram todos funcionários e gestores do Grupo Gama, relacionados diretamente com a gestão de fretes. Já a unidade de análise se classifica como setores responsáveis por atividades e procedimentos relacionadas aos Conhecimentos de Fretes, como o Setor de Compras, Centro de Abastecimento, Administração de Vendas, Expedição, Setor de Qualidade e Setor Contábil.

Em relação à técnica de coleta de dados, o estudo é executado por intermédio de ferramentas como: entrevistas, observações e análise documental (VERGARA, 2013; LAKATOS; MARCONI, 2011).

Para a análise dos dados, coletaram-se inicialmente dados referentes aos valores de fretes dos anos de 2013 e 2014, por meio da análise documental a fim de confrontá-los e identificar o movimento realizado. Nesta atividade constataram-se dois picos sazonais que ocorrem duas vezes ao ano, por meio destes e em conjunto com a empresa, determinou-se a amostra.

No que tange a estipulação da amostra em relação aos fretes, definiu-se que inicialmente seria analisado o primeiro semestre de 2014, por incorporar uma coleção completa. Neste período julgaram-se valores dos fretes de envios e recebimentos de mercadorias. 
Após esta etapa, foi perceptível que fretes de envios das mercadorias possuem predominância em relação ao total, por isto que se utilizou o período de 10 (dez) a 20 (vinte) de março dos anos de 2014 e 2015 , para comparação das atividades. Este período é mais acessado no decorrer da investigação, no entanto, a pesquisa é norteada pelos indicadores teóricos, a todo instante faz-se um julgamento em relação ao período de aplicação, por isto que, obtém variação conforme a análise.

Com a determinação da amostra para a coleta de dados dos fretes, em relação aos valores referentes ao primeiro semestre de 2014 , foram digitados manualmente, pois os documentos se encontravam apenas em estado físico e em arquivos eletrônicos não editáveis impossibilitando tratamento com sistemas.

\section{RESULTADOS E DISCUSSÃO}

Nessa seção será tratada a apresentação e análise dos dados sendo estruturada por tópicos. O primeiro item trata da aplicação de indicadores de fretes na empresa, realizada mediante a proposta de alguns indicadores coletados em pesquisas teóricas, para projetá-los ao contexto estudado. Após no item denominado Outros Indicadores, são utilizados indicadores para analisar várias amostragens e em diversos períodos, que tem como finalidade projetar algumas modificações. O próximo subitem é denominado Análise do preço do frete no modal rodoviário, que são realizadas comparações quantitativas em relação aos preços praticados. Em seguida, tem-se o item Análise referente à qualidade do serviço de frete, que é basicamente uma discussão acerca dos aspectos qualitativos coletados, ou seja, aspectos como a satisfação, entrega no prazo e qualidade da entrega.

Este estudo se dá no âmbito do Grupo Gama, instalado no oeste de Santa Catarina e atua em todo território nacional, atendendo pessoas jurídicas que trabalham com varejo, no segmento de confecções. O problema da presente pesquisa foca a gestão de fretes, atividade que apresenta oportunidades de melhorias.

O grupo iniciou suas atividades no ano de 1990, na época possuía 2 (dois) funcionários e 10 (dez) clientes lojistas, o produto consistia em camisas masculinas. Através de investimentos na busca da profissionalização da gestão, juntamente com ferramentas de marketing, é possível compreender o rápido desenvolvimento da empresa.

Como a Empresa Gama cresceu rapidamente nos últimos anos, considerou-se necessário adaptar os processos às mudanças de forma estratégica. Por conta disto a rotina da empresa possui características relevantes, uma vez que não comporta toda a produção interna. Em 2015 cerca de 55\% dos produtos eram fabricados internamente, 30\% eram encomendados aos terceiros, $14 \%$ eram faccionados e entregues à empresa apenas para aplicação do acabamento e $1 \%$ dos produtos eram importados.

A produção interna é estruturada em sete unidades produtivas, distribuídas entre os municípios de São Carlos, Águas de Chapecó, Planalto Alegre, Saltinho, todas no estado de Santa Catarina e uma unidade localizada em São Paulo, no estado de SP.

Os clientes estão localizados em todo o território nacional, são em média 1.300 lojistas, paralelamente a isto, o quadro funcional é composto por 470 funcionários e o faturamento de 2014 atingiu 68 milhões.

\subsection{Seleção dos indicadores de desempenho aplicados aos fretes}

No que tange aos fluxos e processos relativos aos fretes, a empresa não possui indicadores estruturados para a avaliação do desempenho de fretes. Essa restrição ocorre devido ao rápido crescimento organizacional, onde as mudanças foram constantes e o gerenciamento da empresa não alcança todas as atividades. Com isto, alguns processos foram deixados de lado, porque o foco da empresa é destinado à gestão dos grandes montantes.

Nesse estudo, são relatados resultados apenas referentes aos fretes de envio de mercadoria, ou seja, o envio dos produtos ao consumidor final. É importante ressaltar que esse artigo é decorrente de um estudo maior, em que são analisados outros tipos de fretes da empresa, tais como o recebimento de matéria-prima e movimentação de produtos entre filiais e terceiros. 
A seleção dos indicadores de desempenho capta aspectos referentes à qualidade do serviço prestado, como também, análises de preço e da proporção de atuação. Por meio de conversas realizadas com o gestor financeiro, foi solicitada a inclusão de alguns indicadores de desempenhos, como: o percentual dos fretes por região, por transportadora e por valor da mercadoria em relação as regiões. A demanda pelos indicadores ocorre porque a empresa não possui conhecimento dos percentuais, tampouco, realiza os controles.

Diante desta perspectiva e baseado nos autores Ângelo (2005), Ballou (2006), Fleury, Avila e Wanke (1997) e Rita (2016), propõem-se indicadores de desempenho para o processo de contratação de fretes (Quadro 1 e 2).

Quadro 1 - Indicadores de desempenhos, aplicáveis à análise dos fretes

\begin{tabular}{|c|c|c|c|}
\hline Indicadores & Autores & Objetivo & Padrão \\
\hline Percentual de região & $\begin{array}{c}\text { Definido em } \\
\text { consenso com a } \\
\text { empresa }\end{array}$ & $\begin{array}{c}\text { Para identificar onde há } \\
\text { maior concentração de fretes. }\end{array}$ & $\begin{array}{c}\text { Não há um padrão } \\
\text { preestabelecido }\end{array}$ \\
\hline $\begin{array}{c}\text { Percentual de } \\
\text { transportadora por região } \\
\text { consenso com a } \\
\text { empresa }\end{array}$ & $\begin{array}{c}\text { Para compreender a atuação } \\
\text { das transportadoras por } \\
\text { região. }\end{array}$ & $\begin{array}{c}\text { Não há um padrão } \\
\text { preestabelecido }\end{array}$ \\
\hline $\begin{array}{c}\text { Análises referentes ao } \\
\text { peso e generalidades }\end{array}$ & Ballou (2006) & $\begin{array}{c}\text { O autor comenta que estas } \\
\text { características sensibilizam o } \\
\text { frete. }\end{array}$ & $\begin{array}{c}\text { Não há um padrão } \\
\text { preestabelecido }\end{array}$ \\
\hline $\begin{array}{c}\text { Envio das regiões em } \\
\text { relação ao valor da Nota } \\
\text { fiscal. }\end{array}$ & $\begin{array}{c}\text { Definido em } \\
\text { consenso com a } \\
\text { empresa }\end{array}$ & $\begin{array}{c}\text { Para identificar o envio de } \\
\text { montante por região. }\end{array}$ & $\begin{array}{c}\text { Não há um padrão } \\
\text { preestabelecido }\end{array}$ \\
\hline
\end{tabular}

Fonte: Elaborado pelos Autores (2015).

Também serão aplicados os indicadores citados por Ângelo (2005), porque se pretende obter conhecimento da participação do frete no valor da mercadoria transportada, bem como o valor gasto para expedir uma unidade (uma caixa), com isto é possível medir a variação ao longo dos anos ou então, entre os diferentes modais.

Pretende-se aplicar também os indicadores que avaliam o total de coletas realizadas no prazo e a proporção de erros contidos nos Conhecimentos de Fretes. Desta forma é possível avaliar a qualidade do serviço prestado, já que são fatores que impactam na satisfação dos envolvidos. A síntese dos indicadores aplicados aos fretes de envio está contida no Quadro 2.

Quadro 2 - Indicadores de desempenho, aplicáveis à análise dos fretes de envio de mercadorias

\begin{tabular}{|c|c|c|c|}
\hline Indicadores & Autores & Objetivo & Padrão \\
\hline $\begin{array}{c}\text { Período de entregas } \\
\text { de fretes }\end{array}$ & $\begin{array}{c}\text { Fleury, Avila e Wanke } \\
(1997)\end{array}$ & $\begin{array}{c}\text { Prevê sazonalidades e o } \\
\text { comportamento dos fretes. }\end{array}$ & $\begin{array}{c}\text { Não há um padrão } \\
\text { preestabelecido }\end{array}$ \\
\hline $\begin{array}{c}\text { Frete (R\$) / Valor da } \\
\text { mercadoria (R\$) }\end{array}$ & Ângelo (2005) & $\begin{array}{c}\text { Demonstra a participação do } \\
\text { gasto com transporte sobre } \\
\text { as vendas da empresa. }\end{array}$ & $\begin{array}{c}\text { Não há um padrão } \\
\text { preestabelecido }\end{array}$ \\
\hline $\begin{array}{c}\text { Frete (R\$) /unidade } \\
\text { expedida }\end{array}$ & Ângelo (2005) & $\begin{array}{c}\text { Compreende o custo que } \\
\text { cada unidade possui. }\end{array}$ & $\begin{array}{c}\text { Não há um padrão } \\
\text { preestabelecido }\end{array}$ \\
\hline $\begin{array}{c}\text { Coletas no prazo/total } \\
\text { de coletas }\end{array}$ & Ângelo (2005) & $\begin{array}{c}\text { Identifica o percentual de } \\
\text { coletas realizadas no prazo. }\end{array}$ & $\begin{array}{c}\text { Média nacional de } \\
95 \% \text { a } 98 \%\end{array}$ \\
\hline $\begin{array}{c}\text { Erros de cobrança (R\$) } \\
\text { /total de fretes }\end{array}$ & Ângelo (2005) & $\begin{array}{c}\text { Capta erros de cobrança em } \\
\text { relação ao frete. }\end{array}$ & $\begin{array}{c}\text { Média nacional de } \\
98,5 \%\end{array}$ \\
\hline
\end{tabular}

Fonte: Adaptado de Ballou (2006), Ângelo (2005).

Em relação aos indicadores com padrões preestabelecidos nacionalmente, sugere-se que a empresa busque atingi-los como meta inicial e posteriormente reavalie o padrão. Para os indicadores que ainda não possuem padrões, propõe-se a aplicação durante um determinado período, para identificar qual é a média predominante. Com a determinação dos padrões é possível estabelecer metas de desempenho. 
Também aconselha-se realizar uma avaliação periódica dos indicadores sugeridos, de forma a validálos ao longo do tempo para garantir sua utilidade na gestão de fretes. É possível adaptá-los e ajustá-los conforme a necessidade.

As seções seguintes simulam os indicadores de desempenho sugeridos, sobre fretes de envio, respectivamente.

\subsection{Aplicação de indicadores aos fretes da empresa}

O primeiro indicador elencado é o percentual por região, com a finalidade de fornecer subsídios que facilitam a negociação com as transportadoras (Gráfico 1).

Notadamente, os fretes enviados são primordialmente para as Regiões Sudeste (40\%) e Sul (32\%). Sendo que, a Nordeste também se destaca, todavia, com menor proporção (18\%). Mediante a obtenção destas informações é possível projetar a demanda do transporte, por período e região, para fornecer a transportadora negociante uma projeção dos fretes enviados.

Gráfico 1 - Fretes enviados por região brasileira, primeiro semestre de 2014

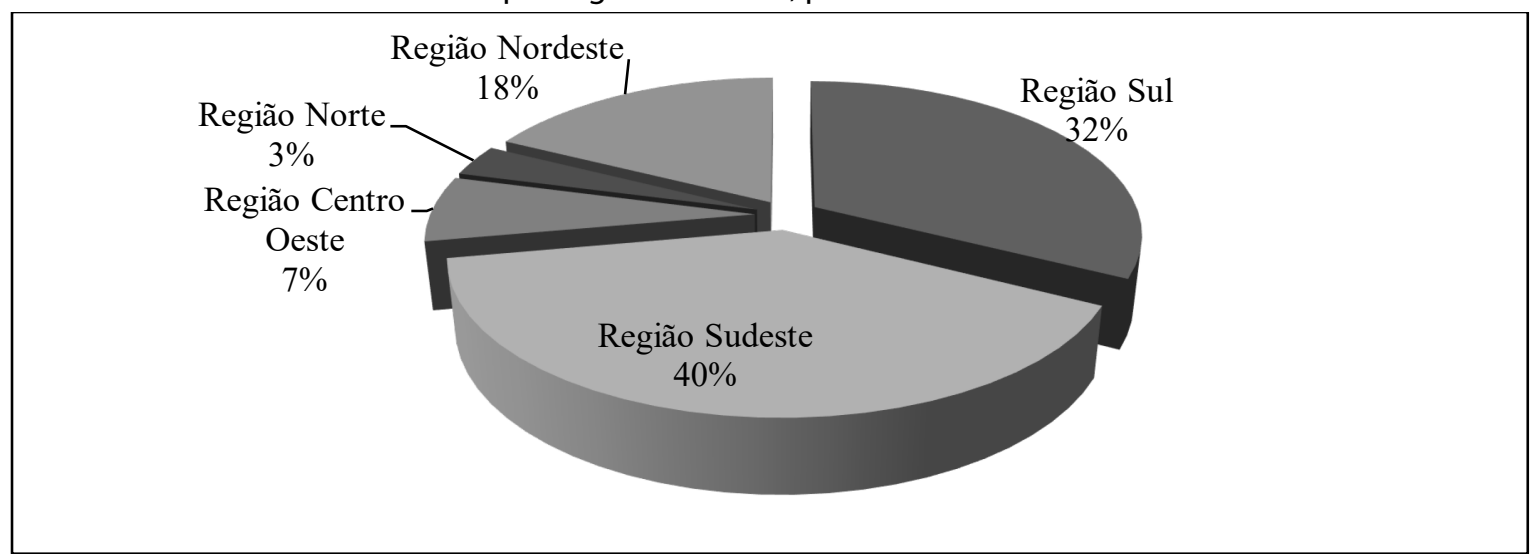

Fonte: Elaborado pelos Autores (2015).

Pode-se avaliar o percentual por transportadora utilizada para a execução dos fretes de envio, onde é possível perceber a concorrência existente (Gráfico 2). Neste as Transportadoras C e D barganham grande parte da atividade, sendo que a C possui vantagens em todas as regiões. Inclusive, na Região Sul assume $56 \%$ e o restante é disputado pelas Transportadoras D (29\%) e B (14\%).

Gráfico 2 - Fretes enviados por transportadoras e região, primeiro semestre de 2014

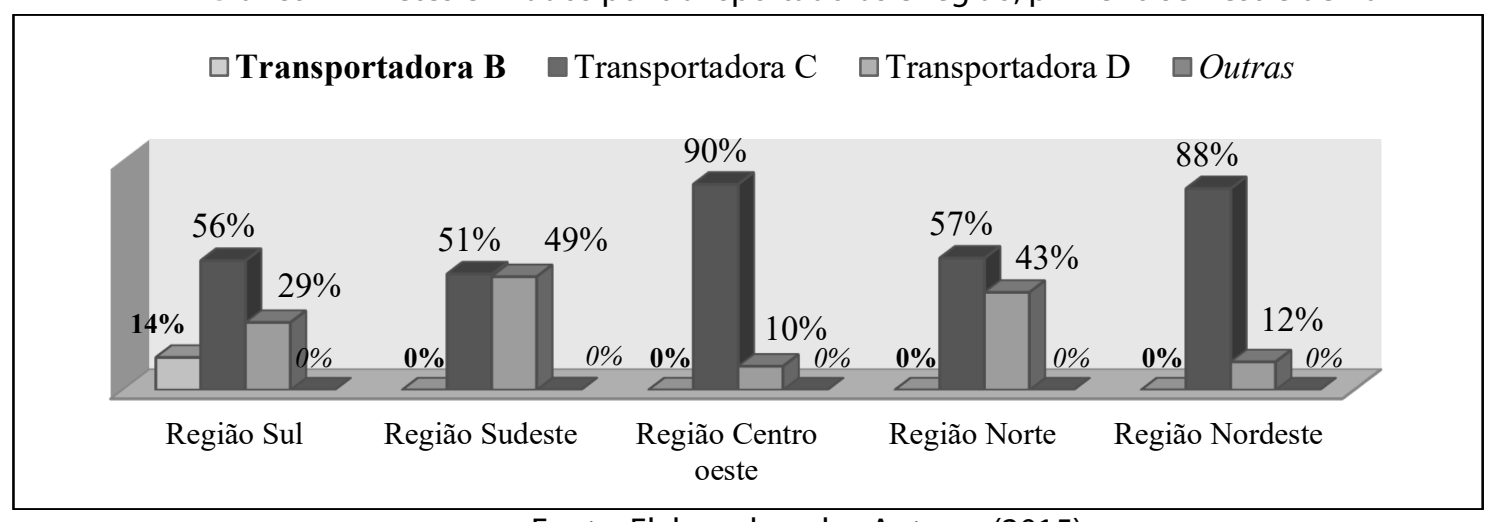

Fonte: Elaborado pelos Autores (2015). 
Esta concorrência ocorre devido ao preço praticado ser semelhante. Porém, em conversa com o gestor financeiro, identificou-se que a última possui problemas de qualidade, como a perda de mercadorias e outras reclamações realizadas pelos clientes. Só que, como tem um preço competitivo, ainda possui participação no período mesmo que menor.

A Tabela 1 mostra a composição do frete de envio, em que predominantemente a taxa Frete Peso abrange $78 \%$ do valor. É classificada como a mais representativa, porque as regiões mais distantes como o Nordeste (83\%) e Norte (78\%) possuem maior Frete Peso, devido à tabela de precificação vigente.

Já, a Generalidade representa a segunda maior incidência, que é de 13\% sobre o total, porque em regiões como a Centro Oeste (18\%) e Norte (15\%), as Generalidades são mais presentes, devido à distância do ponto de origem e destino e aos grandes centros urbanos existentes.

Tabela 2 - Composição do frete enviado, primeiro semestre de 2014

\begin{tabular}{ccccc}
\hline Regiões & Generalidades & Frete peso & Frete Valor & Total \\
Região Sul & $13 \%$ & $75 \%$ & $11 \%$ & $100 \%$ \\
Região Sudeste & $14 \%$ & $76 \%$ & $9 \%$ & $100 \%$ \\
Região Centro-oeste & $18 \%$ & $75 \%$ & $6 \%$ & $100 \%$ \\
Região Norte & $15 \%$ & $78 \%$ & $5 \%$ & $100 \%$ \\
Região Nordeste & $10 \%$ & $83 \%$ & $5 \%$ & $100 \%$ \\
Todas as regiões & $\mathbf{1 3 \%}$ & $\mathbf{7 8 \%}$ & $\mathbf{8 \%}$ & $\mathbf{1 0 0 \%}$ \\
\hline
\end{tabular}

Fonte: Elaborado pelos Autores (2015).

Para compreender o percentual do valor do frete, peso ou valor da mercadoria sobre as regiões, fazse uso da Tabela 2. É possível perceber que 39\% do peso são enviados para a Região Sudeste, esta por sua vez também tem maior valor de frete (36\%) e valor da mercadoria (44\%).

Um fato que denota atenção é a Região Nordeste, porque é classificada como a terceira maior recebedora do peso (17\%), bem como do valor da mercadoria (17\%). Entretanto, se iguala a Região Sul (na segunda posição) no que tange ao recebimento do valor do frete, com $25 \%$. Isto reforça o fato de que os fretes enviados para Região Nordeste possuem maior valor, quando comparado às demais regiões.

Tabela 3 - Comportamento do peso bruto, frete e valor da mercadoria enviada, primeiro semestre de 2014

\begin{tabular}{cccc}
\hline Regiões & Peso Bruto & Frete & Valor da Mercadoria \\
Região Sul & $34 \%$ & $25 \%$ & $30 \%$ \\
Região Sudeste & $39 \%$ & $36 \%$ & $44 \%$ \\
Região Centro-oeste & $7 \%$ & $7 \%$ & $6 \%$ \\
Região Norte & $3 \%$ & $6 \%$ & $3 \%$ \\
Região Nordeste & $17 \%$ & $25 \%$ & $17 \%$ \\
Total & $\mathbf{1 0 0 \%}$ & $\mathbf{1 0 0 \%}$ & $\mathbf{1 0 0 \%}$ \\
\hline
\end{tabular}

Fonte: Elaborado pelos Autores (2015).

A seguir, fez-se uma análise dos pesos aferidos pela transportadora e empresa, já que possui influência no valor do frete, como é possível visualizar as diferenças existentes (tabela 3). É possível constatar uma variação de $-0,02 \%$ até $-48 \%$, a qual beneficia sempre a transportadora.

A diferença entre os pesos neste período pode ter sido provocada devido ao método de cubagem, que era ativo no primeiro semestre de 2014. Ainda, a variação pode ter sido agravada pelo fato de não haver nenhum tipo de controle em relação aos preços estimados e realizados.

É possível perceber que há uma variação levemente maior na Transportadora $D$, quando comparada a ponto após $C$, ou seja, neste período provavelmente foi cobrada a taxa de peso maior do que o peso real. Fator este identificado pela empresa na época e buscado ressarcimento. 
Observa-se que o detalhamento dos pesos aferidos, está contido apenas no Conhecimento de Frete, que é um arquivo não editável. Ao considerar que o peso é uma unidade de medida responsável pela determinação do valor do frete, sugere-se solicitar as transportadoras o formato digital do documento, para que desta forma seja possível realizar análises.

Tabela 4 - Comparação do peso aferidos pela transportadora e empresa, primeiro semestre de 2014

\begin{tabular}{ccc}
\hline Transportadora/região & Variação (kg) & Variação (\%) \\
\hline Transportadora C & $-706,53$ & $-1 \%$ \\
Transportadora D & $-265,20$ & $-3 \%$ \\
\hline Transportadora C & Região Sudeste & $-0,02 \%$ \\
Transportadora D & $-23,39$ & $-28 \%$ \\
& $-7.254,89$ & \\
\hline Transportadora C & Região Centro-oeste & $-12 \%$ \\
Transportadora D & $-2.425,69$ & $-23 \%$ \\
& $-266,10$ & $-2 \%$ \\
\hline Transportadora C & Região Norte & $-27 \%$ \\
Transportadora D & $-174,90$ & \\
\hline Transportadora C & $-523,17$ & $-0,23 \%$ \\
Transportadora D & Região Nordeste & $-48 \%$ \\
\hline
\end{tabular}

Fonte: Elaborado pelos Autores (2015).

Com finalidade de conhecer a participação do valor do frete sobre as vendas, o próximo indicador é demonstrado na Tabela 4, onde é possível identificar a variação em kg e \%. O comportamento deste indicador é semelhante ao anterior, em que se percebem diferenças nas regiões mais distantes, como Norte que apresenta 3,42\% do valor do frete sobre as vendas de mercadorias. Em geral, é possível apontar que o valor do frete representa $2,12 \%$ do valor das mercadorias vendidas.

Tabela 5 - Proporção do frete de envio sobre o valor da mercadoria, primeiro semestre de 2014

$\begin{array}{cr}\text { Regiões } & \text { Frete / valor } \mathbf{~ d a ~} \mathbf{m} \\ \text { Região Sul } & \mathrm{R} \$ 1,34 \\ \text { Região Sudeste } & \mathrm{R} \$ 1,36 \\ \text { Região Centro-oeste } & \mathrm{R} \$ 2,01 \\ \text { Região Norte } & \mathrm{R} \$ 3,42 \\ \text { Região Nordeste } & \mathrm{R} \$ 2,47 \\ \text { Total } & \mathbf{R} \mathbf{2 , 1 2}\end{array}$

Fonte: Elaborado pelos Autores (2015).

Por fim, foi possível compreender que há diferenças entre o peso aferido pela empresa e transportadora, sendo que sempre beneficia o terceiro. Ainda, permitiu afirmar que há uma proporção relevante de frete destinado às Regiões Sudeste e Sul, com menor parcela para a Norte e Nordeste. Sendo que as últimas possuem maior participação no valor gasto com frete. 


\subsection{Outros indicadores utilizados na análise dos fretes na empresa}

Nessa seção utilizaram-se várias amostras de diversos períodos diferentes, pois, pretendeu-se obter análises recentes desses indicadores, sem que ocorrências decorridas no tempo interfiram.

\subsubsection{Análise do preço do frete no modal rodoviário}

Para realizar a análise a seguir foram utilizados dados referentes ao período de 10 (dez) a 20 (vinte) de março de 2014 e no mesmo período de 2015. O indicador mostra o valor do frete (R\$) e sua relação pela unidade (em caixas) expedida, nos dois períodos. A Tabela 6 demonstra que, para transportar uma unidade da mercadoria foram gastos em média de $\mathrm{R} \$ 7,73 \mathrm{em} 2015$. No entanto, em 2014 se gastava $\mathrm{R} \$ 15,21$ por caixa expedida. Esta análise comprova que a empresa obteve um ganho no valor do frete, o qual é fruto da negociação realizada este ano.

Tabela 6 - Valor por unidade (caixa) expedida, comparação entre 2014 e 2015

\begin{tabular}{ccc}
\hline & $\mathbf{2 0 1 5}$ & \\
Unidades expedidas & Total frete & Frete por unidade \\
2.271 (em caixas) & $\mathrm{R} \$ 24.296,00$ & $\mathrm{R} \$ 7,73$ \\
\hline & $\mathbf{2 0 1 4}$ & \\
Unidades expedidas & Total frete & Frete por unidade \\
3.144 (em caixas) & $\mathrm{R} \$ 34.531,19$ & $\mathrm{R} \$ 15,21$ \\
\hline
\end{tabular}

Fonte: Adaptado de Ângelo (2005).

Este indicador permite também realizar a comparação entre outros modais de transporte, como por exemplo, o aéreo. Mesmo que a empresa em estudo realize o transporte de mercadorias prioritariamente pelo modal rodoviário, em 2014 foi emitido um Conhecimento de Frete aéreo, com isto, é possível comparar o valor unitário, o qual representa um montante de $\mathrm{R} \$ 423,65$.

Portanto, percebe-se que diante destas opções, o modal rodoviário é o mais indicado, para envio de mercadorias. Até porque o custo com transporte aéreo é demasiadamente alto e ainda não se tem subsídios suficientes para barganhar este tipo de serviço.

\subsubsection{Análise referente à qualidade do serviço de frete}

Para a análise das coletas realizadas no prazo, buscou-se selecionar um período em que os fatores externos não interferiram, em exemplo, o ano de 2015 foi marcado pelas greves dos motoristas, fator este que modificou o desempenho dos terceiros.

Então, por meio dos dados fornecidos pelo Transportador C, referentes ao período de fevereiro de 2014 até maio de 2014, realizou-se a aplicação do indicador que avalia as entregas realizadas no prazo, conforme demonstrado na Tabela 7.

Com os resultados obtidos, é possível compará-los com os dados de Ângelo (2005), que afirma que a média nacional desta atividade é de $98 \%$ e $95 \%$. Ao considerar as entregas no prazo realizadas pela Transportadora C, percebe-se que de modo geral, a atividade se encontra fora da média nacional, com êxito em $86 \%$. Isto ocorre devido a algumas regiões serem mais distantes, como exemplo a Região Nordeste e Norte, que possuem uma média de entrega no prazo, de $76 \%$ e $78 \%$, respectivamente.

Em uma análise realizada da Tabela 7, juntamente com a perspectiva de Ângelo (2005), define-se que a meta ideal é $98 \%$, uma vez que é considerada a média nacional. Nesse caso, nenhuma região atinge o padrão esperado. 
Tabela 7 - Entregas realizadas, fevereiro a maio de 2014

\begin{tabular}{ccc}
\hline Regiões & Entregas no prazo & Entregas Fora do prazo \\
Região Centro-oeste & $97 \%$ & $3 \%$ \\
Região Nordeste & $76 \%$ & $24 \%$ \\
Região Norte & $78 \%$ & $22 \%$ \\
Região Sudeste & $93 \%$ & $7 \%$ \\
Região Sul & $92 \%$ & $8 \%$ \\
Total geral & $\mathbf{8 6 \%}$ & $\mathbf{1 4 \%}$ \\
\hline
\end{tabular}

Fonte: Adaptado de Ângelo (2005).

As próximas análises são realizadas mediante a amostra de 10 (dez) a 20 (vinte) de março de 2015, período este que possui as informações completas. Ao constatar que a Transportadora $C$ tem exclusividade no transporte das mercadorias enviadas, buscou-se resgatar a ferramenta que o Setor de Expedição utilizava para controlar e identificar qual terceiro possuía o menor e o segundo menor valor do frete.

Com os dados coletados, foram digitados os pesos aferidos na empresa e o valor da mercadoria na planilha do Excel", esta comparação foi realizada individualmente (frete a frete) e o comportamento obtido foi registrado em outra planilha. Com a junção das informações constatou-se que $17 \%$ dos fretes realizados no período, não indicam a Transportadora C como a opção de menor custo. Ou seja, há outras opções na carteira de transportadora em que o preço é menor.

Mediante esta análise, os valores dos fretes estimados foram comparados com os realizados, a diferença gerou subsídios para aplicar no indicador que avalia os erros de cobrança obtidos nos conhecimentos dos fretes. A Tabela 8 demonstra que o cálculo, obteve 1,64\% de erro de cobrança em relação ao total dos fretes, isto quer dizer que $98,36 \%$ dos documentos não possuem erro.

Ao considerar que a média nacional é 98,5\%, afirma-se que a Transportadora C está abaixo da meta, então mesmo que o valor seja pequeno é possível apontar que existem erros.

Tabela 8 - Erros de cobrança dos Conhecimentos de Fretes, em 2015

\begin{tabular}{ccc}
\hline Erros de cobrança (R\$) & Valor com frete & Erros/fretes \\
$\mathrm{R} \$ 788,75$ & $\mathrm{R} \$ 48.132,01$ & $1,64 \%$ \\
\hline
\end{tabular}

Fonte: Adaptado de Ângelo (2005).

A análise permitiu identificar que o Grupo Gama obteve um ganho em relação ao valor do frete, isto é consequência da negociação realizada nos primeiros meses de 2015. Todavia, sugere-se que a empresa se atente aos aspectos que influenciam a qualidade do serviço prestado, porque, dentre os indicadores aplicados os quais visam avaliar o desempenho da transportadora, apontaram um desempenho abaixo do esperado.

Por fim, sugere-se que a empresa continue aplicando estes indicadores periodicamente, de modo a avaliar o desempenho da transportadora, bem como o comportamento do frete. Com isto, é possível identificar a viabilidade dos indicadores de modo a ajustá-los conforme a necessidade.

\section{CONSIDERAÇÕES FINAIS}

O presente estudo possibilitou identificar quais indicadores podem ser aplicados para realizar a gestão do frete no modal rodoviário. Mesmo que a teoria não estabeleça indicadores para avaliar diretamente a gestão da contratação de terceiros para realização do frete, com a teoria existente é possível realizar inferências e criar opções que permitem realizar julgamentos.

A pesquisa se deu por meio do levantamento dos volumes, frequência e valores relativos aos fretes, porque, até então, a empresa não fazia uso de nenhuma ferramenta de controle e nem a gestão desta área. Assim, investigou-se por intermédio da análise documental, onde foi possível identificar alguns dados para realizar generalizações. 
Dentre as limitações encontradas na pesquisa, é possível apontar a não estruturação da gestão de fretes por parte da empresa em estudo. Esse fator intensificou inicialmente o desconhecimento da proporção dos conhecimentos de frete, bem como, dos períodos para análises. Isso requereu o uso das generalizações, no que tange às classificações do frete.

Por fim, destaca-se que novos trabalhos podem vir a ser desenvolvidos a partir deste estudo. Como sugestão cita-se a aplicação da Pesquisa Operacional na gestão dos fretes por peso. Ainda, sugere-se executar um estudo referente a viabilidade do uso de softwares para a gestão dos fretes.

\section{REFERÊNCIAS}

ÂNGELO, L. B. Indicadores de desempenho logístico. 2005. Dissertação (Mestrado) - Universidade Federal de Santa Catarina, 2005.

APPOLINÁRIO, Fábio. Metodologia da ciência: filosofia e prática da pesquisa. 2. ed. São Paulo: Cengage Learning, 2012.

BALLOU, Ronald H. Gerenciamento da cadeia de suprimentos: planejamento, organização e logística empresarial. Porto Alegre: Bookman, 2006.

BOWERSOX, Donald J. et al. Gestão logística da cadeia de suprimentos. 4. ed. Porto Alegre: AMGH, 2014.

CASTIGLIONI, José Antonio de Mattos; NASCIMENTO, Francisco Carlos do. Custos de processos logísticos. 1. ed. São Paulo: Érica, 2014.

CNT. Frete deve ter reajuste médio de $14 \%$ neste ano: elevação dos custos e defasagem de preços provocação aumento. 2014. Disponível em: https://www.cnt.org.br/agencia-cnt/ntc-logistica-preco-fretedefasagem-economia-transporte-31012014. Acesso em: 20 jun. 2019.

CRESWELL, John W. Projeto de pesquisa: Métodos qualitativo, quantitativo e misto. 3. ed. Porto Alegre: Artmed, 2010.

DIAS, Marco Aurélio P. Administração de materiais: princípios, conceitos e gestão. 6 ed. São Paulo: Atlas, 2012.

FISCHMANN, Adalberto A.; ZILBER, Moisés A. Utilização de indicadores de desempenho como instrumento de suporte à gestão estratégica. [1999]. Disponível em: http://www.anpad.org.br/admin/pdf/enanpad1999-ae-11.pdf. Acesso em: 09 fev. 2016.

FLEURY, Paulo Fernando; AVILA, Marcos Gonçalves; WANKE, Peter. Em busca da Eficiência no transporte terceirizado: estrutura de custos, parcerias e eliminação de desperdícios. Revista Gestão \& Produção, v. 4, n. 2, p. 219-233, ago. 1997. Disponível em: http://www.scielo.br/pdf/gp/v4n2/a09v4n2.pdf. Acesso em: 27 abr. 2015.

FUNDAÇÃO DOM CABRAL. Custos logísticos no Brasil. Núcleo de logística, Supply Chain e Infraestrutura. 2017. Disponível em: https://www.fdc.org.br/conhecimento-site/nucleos-de-pesquisasite/Materiais/pesquisa-custos-logisticos2017.pdf. Acesso em 10 jun. 2019.

LAKATOS, Eva Maria; MARCONI, Marina de Andrade. Fundamentos de metodologia científica. 7. ed. São Paulo: Atlas, 2011.

MARTINS, Ricardo S.; LOBO, Débora da Silva; ARAÚJO, Maria da Piedade. Sazonalidade nos fretes e preferências dos embargadores no mercado de transporte de granéis agrícolas. Revista de Economia e Administração, Toledo, PR, v. 4, n. 1, p. 68-96, jan./mar. 2005. Disponível em: http://www.cepead.face.ufmg.br/files/nucleos/nipe log/Artigo6.pdf. Acesso em: 27 abr. 2015. 
MARTINS, Roberto Antonio; COSTA NETO, Pedro Luiz de Oliveira. Indicadores de desempenho para a gestão pela qualidade total: uma proposta de sistematização. Revista Gestão \& Produção, São Paulo, v. 3, n. 3, p. 298-311, dez. 1998. Disponível em: http://www.dep.ufscar.br/admin/upload/ARTIGO 1148385976.PDF. Acesso em: 27 abr. 2015.

RITA, João L. de S. Estratégia de contratação de fretes: um estudo de caso na indústria de cimento. Dissertação (Mestrado em Engenharia da Produção) - Pontifícia Universidade Católica do Rio de Janeiro, Rio de Janeiro, 2016. Disponível em: http://www.maxwell.vrac.puc-rio.br/23973/23973 1.PDF. Acesso em: 09 fev. 2016.

TABOADA, Carlos. Gestão de tecnologia e inovação na logística. Curitiba: IESDE Brasil S.A., 2009.

VERGARA, Sylvia Constant. Projetos e relatórios de pesquisa em administração. São Paulo: Atlas S.A, 2013.

VIEIRA, Guilherme Berman Borges. Transporte internacional de cargas. 2. ed. São Paulo: Aduaneiras, 2003.

YIN, Robert K. Estudo de caso: planejamento e métodos. 4. ed. Porto Alegre: Bookman, 2010. 